\title{
Dehydroglyasperin $C$, a component of liquorice, attenuates proliferation and migration induced by platelet-derived growth factor in human arterial smooth muscle cells
}

\author{
Hyo Jung Kim $†$, Byung-Yoon $\mathrm{Cha}^{2} \dagger$, In Sil Park ${ }^{1}$, Ji Sun $\mathrm{Lim}^{1}$, Je-Tae Woo ${ }^{2}$ and Jong-Sang Kim ${ }^{1 *}$ \\ ${ }^{1}$ School of Applied Biosciences, Food Science and Biotechnology, BK21 Research Team for Developing Functional Health \\ Food Materials, Kyungpook National University, Daegu 702-701, Republic of Korea \\ ${ }^{2}$ Research Institute for Biological Functions, Chubu University, 1200 Matsumoto, Kasugai, Aichi, Japan \\ (Submitted 10 August 2012 - Final revision received 2 November 2012 - Accepted 5 November 2012 - First published online 9 January 2013)
}

\section{Abstract}

Liquorice is one of the botanicals used frequently as a traditional medicine in the West and in the East. Platelet-derived growth factor (PDGF)-BB is involved in the development of CVD by inducing abnormal proliferation and migration of vascular smooth muscle cells. In our preliminary study, dehydroglyasperin C (DGC), an active compound of liquorice, showed strong antioxidant activity. Since phytochemicals with antioxidant activities showed beneficial effects on chronic inflammatory diseases, the present study aimed to investigate the effects of DGC on PDGF-induced proliferation and migration of human aortic smooth muscle cells (HASMC). Treatment of HASMC with DGC for $24 \mathrm{~h}$ significantly decreased PDGF-induced cell number and DNA synthesis in a dose-dependent manner without any cytotoxicity, as demonstrated by the 3-(4,5-dimethyl-thiazol-2-yl)-2,5-diphenyltetrazolium bromide test and thymidine incorporation. Upon cell cycle analysis, DGC blocked the PDGF-induced progression through the $G_{0} / G_{1}$ to $S$ phase of the cell cycle, and down-regulated the expression of cyclin-dependent kinase (CDK); 2, cyclin E, CDK4 and cyclin D1. Furthermore, DGC significantly attenuated PDGF-stimulated phosphorylation of PDGF receptor- $\beta$, phospholipase C- $\gamma 1$, AKT and extracellular-regulated kinase $1 / 2$, and DGC inhibited cell migration and the dissociation of actin filaments by PDGF. In a rat vascular balloon injury model, DGC suppressed an excessive reduction in luminal diameters and neointimal formation compared with the control group. These results demonstrate the mechanistic basis for the prevention of CVD and the potential therapeutic properties of DGC.

\section{Key words: Dehydroglyasperin C: Vascular smooth muscle cells: Platelet-derived growth factor-BB: Platelet-derived growth} factor signalling pathway: Proliferation: Migration

Accumulation of vascular smooth muscle cells (VSMC) is a key event in the formation and development of lesions in atherosclerosis. The excessive accumulation of VSMC is due to a combination of directed migration from the media into the intima of the artery accompanied by proliferation and possibly decreased apoptosis. The proliferation and migration of VSMC are associated with vascular change through intimal lesion formation, and these can be induced by growth factors, such as PDGF. PDGF is expressed in various vascular cells such as VSMC, endothelial cells, platelets and macrophages, and platelet-derived growth factor-BB (PDGF-BB) is a more potent inducer of VSMC proliferation and migration than PDGF-AA and $-\mathrm{AB}^{(1-4)}$.
However, the mechanisms related to the PDGF-stimulated proliferation and migration of smooth muscle cells have not yet been fully elucidated. Several studies have shown that PDGF disrupts actin filament assembly and increases the expression of the PDGF- $\beta$ receptor (PDGFR- $\beta$ ) in injured carotid arteries ${ }^{(5)}$. PDGF-BB developed intimal thickening and VSMC migration from the media to the intima in a rat model of angioplasty ${ }^{(6)}$. Consistent with the results, it has been shown that a selective PDGF-receptor tyrosine kinase blocker attenuated activation, migration, proliferation and neointimal formation after balloon injury in a swine model ${ }^{(7)}$. Some studies have also reported that phosphorylations of mitogenactivated protein kinases are related to PDGF-mediated cytoplasmic signalling such as DNA synthesis and the

Abbreviations: CDK, Cyclin-dependent kinase; DGC, dehydroglyasperin C; ERK, extracellular-regulated kinase; HASMC, human aortic smooth muscle cells;
PDGF, platelet-derived growth factor; PDGFR- $\beta$, platelet-derived growth factor- $\beta$ receptor; PLC $\gamma 1$, phospholipase C- $\gamma 1$; VSMC, vascular smooth muscle cells.

Corresponding author: J.-S. Kim, fax +82539506750, email vision@knu.ac.kr

† Both authors contributed equally to this work. 
mitogenic process ${ }^{(8)}$, and the PDGF-induced activation of phospholipase C- $\gamma 1$ (PLC $\gamma 1$ ) and phosphatidylinositol-3 kinase/AKT is implicated in the induction of smooth muscle cell migration ${ }^{(9)}$. Furthermore, PDGF generates reactive oxygen species as a mediator of signal transduction to elicit its mitogenic effect. Thus, PDGF-BB and PDGFR signal transduction are essential for the development and pathogenesis of proliferative vascular disease.

Recently, several compounds from plants have exhibited beneficial effects in the regulation of atherosclerosis, heart diseases and autoimmune disorders. The antioxidant properties of these kinds of compounds have been suggested to explain their beneficial effects. Phytochemicals present in the Leguminosae family of plants have an inhibitory mechanism for PDGF-induced mitogenic signalling in mesangial cells ${ }^{(10)}$. Treatment with phytochemicals derived from soyabean by a biotic elicitor in human aortic VSMC resulted in a significant inhibition of PDGF-mediated cellular proliferation and migration $^{(11)}$.

Liquorice, the Glycyrrbiza species (Glycyrrbiza uralensis Fisher), is one of the most frequently utilised plants as a traditional medicine and a natural sweetener since Egyptian, Greek and Roman times, and ancient China ${ }^{(12)}$. Besides antioxidant activity, liquorice root possesses potential beneficial effects against inflammation, viral infection, tumorigenesis, malaria and $\mathrm{CVD}^{(13-20)}$, as well as peptic ulcers, hepatitis C, and pulmonary and skin diseases ${ }^{(21,22)}$

Glycycoumarin ( $G$. uralensis), glabridin (Glycyrrbiza glabra) and licochalcone A (Glycyrrbiza inflata) have the potential to function as indicators of liquorice ${ }^{(23)}$. As the other bioactive constituents present in liquorice, dehydroglyasperin C (DGC) and dehydroglyasperin D have shown increased PPAR- $\gamma$ ligand-binding activity and anti-inflamma-

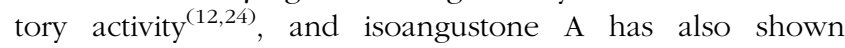
antibacterial effects against methicillin-resistant Staphylococcus aureus (MRSA) strains ${ }^{(25)}$, suppression of inflammation in renal mesangial cells ${ }^{(26)}$, and induction of $G_{1}$ arrest and apoptosis in prostate cancer cells ${ }^{(27,28)}$

Although the beneficial effect of liquorice has been postulated in several studies, the protective effect of DGC, a bioactive constituent of liquorice root, on atherosclerosis is not yet known. In the present study, the anti-atherosclerotic effects of DGC were evaluated, and it was found that this compound could inhibit PDGF-stimulated proliferation and migration of human aortic smooth muscle cells (HASMC).

\section{Experimental methods}

\section{Preparation of dehydroglyasperin C}

Purification of DGC from liquorice root was performed according to the method described previously ${ }^{(29)}$. Briefly, the $n$-hexane-ethanol extract of $G$. uralensis $(90 \mathrm{~g}, 0.9 \%$ yield) was produced by dip extraction with $n$-hexane-ethanol at a ratio of $9: 1(\mathrm{v} / \mathrm{v})$ of dried and ground roots of $G$. uralensis $(1 \mathrm{~kg})$. A portion of the extract $(5 \cdot 2 \mathrm{~g})$ was subjected to flash column chromatography with silica gel (Macherey-Nagel Kieselgel), eluted by gradient systems of $n$-hexane-ethyl acetate

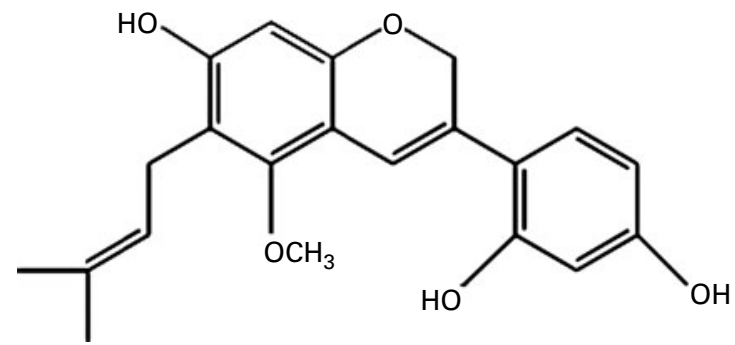

Fig. 1. Molecular structure of dehydroglyasperin C.

$(5: 5, \mathrm{v} / \mathrm{v})$ to obtain twenty fractions. The fractions $(0 \cdot 7 \mathrm{~g})$ showing NAD (P)H:quinone oxidoreductase 1 (NQO1) induction activity were combined and further purified by recrystallisation to recover compound $1(35 \mathrm{mg})$. The structure of the compound was elucidated as DGC (Fig. 1) by comparison of the spectral data with an authentic sample.

\section{Cell culture}

HASMC were obtained from Cascade Biologics, Inc. For routine maintenance, cells were grown in Dulbecco's modified Eagle's medium (Gibco) supplemented with $10 \%$ heat-inactivated fetal bovine serum at $37^{\circ} \mathrm{C}$ in an atmosphere of $5 \% \mathrm{CO}_{2}-95 \%$ air under saturating humidity and passaged every week (1:4 split ratio) by trypsinisation with $0.25 \%$ trypsin/0.02\% EDTA sodium salt solution (Thermo Fisher Scientific, Inc.).

\section{Cell proliferation assay}

The experimental procedures were performed according to previously described methods with some modifications. Briefly, HASMC were trypsinised and plated into ninety-well plates with DMEM at an initial concentration of $1 \times 10^{4}$ cells per well, and incubated in an atmosphere consisting of $5 \%$ $\mathrm{CO}_{2}$ in air at $37^{\circ} \mathrm{C}$ for $24 \mathrm{~h}$. Then, the medium was removed and replaced by a medium containing various concentrations of the test compounds in serum-free DMEM. The bioassay was terminated on day 1 by removing the medium from the wells, and adding 3-(4,5-dimethyl-thiazol-2-yl)-2,5-diphenyltetrazolium bromide solution $(0.5 \mathrm{mg} / \mathrm{ml}$ in phenol red-free culture medium). After $2 \mathrm{~h}$, the solution was removed and $200 \mu \mathrm{l}$ dimethyl sulphoxide was added. After $10 \mathrm{~min}$, absorbance was determined at $540 \mathrm{~nm}$ by a microplate reader (Tecan). Cell proliferation of each group was calculated as the relative absorbance of the treatment group to the control.

\section{DNA synthesis assay}

Thymidine incorporation experiments were carried out according to a previously described method ${ }^{(30)}$. HASMC were cultured until they reached about $40 \%$ confluency. The culture medium was replaced with serum-free medium and incubated for $24 \mathrm{~h}$. The serum-deprived cells were then preincubated with DGC for $24 \mathrm{~h}$ and stimulated with/without PDGF or with/without DGC for $20 \mathrm{~h}$. After the incubation period, $1 \mu \mathrm{Ci}$, (37 kBq) of $\left[{ }^{3} \mathrm{H}\right]$ thymidine was added to the 
cultures and incubated for $4 \mathrm{~h}$ at $37^{\circ} \mathrm{C}$. The cells were harvested using a Universal Harvester (Perkin Elmer), and transferred to a GF/C filter (Perkin Elmer). The filter was dried and the level of radioactivity was determined using a microplate scintillation and luminescence counter (TopCount NXT; Perkin Elmer). The values were calculated from absolute counts to a percentage of the control to allow comparison between the experimental groups.

\section{Cell cycle analysis}

Cell-cycle progression analysis was measured as described previously $^{(31)}$. HASMC were seeded in six-well plates at $2 \times 10^{5}$ cells/well and incubated until the cell density reached to $80 \%$ confluency; thereafter, the medium was replaced with serum-free medium and incubated for $24 \mathrm{~h}$. The cells were then pre-incubated with DGC for $24 \mathrm{~h}$ and stimulated with/ without PDGF or with/without DGC for $24 \mathrm{~h}$. HASMC were harvested, resuspended in $70 \%$ ethanol and incubated at $-20^{\circ} \mathrm{C}$ for $4 \mathrm{~h}$. The fixed cells were washed twice with PBS, and incubated at $37^{\circ} \mathrm{C}$ for $60 \mathrm{~min}$ using a solution containing DNase-free RNase $(200 \mu \mathrm{g} / \mathrm{ml})$. After incubation, the cells were stained with propidium iodide $(50 \mu \mathrm{g} / \mathrm{ml})$ at $4^{\circ} \mathrm{C}$ for $30 \mathrm{~min}$ and subjected to a flow cytometric analysis (Becton Dickinson).

\section{Migration assay}

Cell migration was measured with a modified Boyden transwell chamber (twenty-four-well plate) assay as described in our previous study ${ }^{(30)}$. Starved cells were trypsinised and cell suspension in a basal medium $\left(500 \mu \mathrm{l}, 5 \times 10^{4}\right.$ cells/well) was seeded in the upper chamber. Then, $760 \mu \mathrm{l}$ of serum-free medium with or without experimental compounds were added to the lower chamber. After incubation for $24 \mathrm{~h}$, the cells were labelled by the fluorescence dye calcein acetoxymethyl ester $(4 \mu \mathrm{g} / \mathrm{ml})$. The cells that migrated to the lower chamber were measured with a fluorescence microplate reader at an excitation wavelength of $485 \mathrm{~nm}$ and an emission wavelength of $530 \mathrm{~nm}$. Each treatment was repeated in three independent transwells.

\section{Western blotting}

HASMC were homogenised in pre-cooled radioimmunoprecipitation assay buffer ( $\mathrm{pH} 7 \cdot 4$ ) containing $50 \mathrm{~mm}-$ Tris-Cl, $150 \mathrm{~mm}-\mathrm{NaCl}, \quad 1 \mathrm{~mm}-\mathrm{EDTA}, \quad 1 \%$ Triton-X, $0.5 \%$ sodium deoxycholate and $0 \cdot 1 \%$ SDS. The homogenates were cleared by centrifugation at $7600 \mathrm{~g}$ for $5 \mathrm{~min}$ at $4^{\circ} \mathrm{C}$, and the supernatants were denatured in sample buffer for $5 \mathrm{~min}$ at $95^{\circ} \mathrm{C}$. Proteins were separated by electrophoresis on a $10 \%$ SDS-polyacrylamide gel for $1.5 \mathrm{~h}$ at $70-150 \mathrm{~V}$ and transferred onto nitrocellulose membranes (Amersham Biosciences) for $2 \mathrm{~h}$ at $250 \mathrm{~mA}$. The membranes were incubated with antibodies to p-PDGFR- $\beta$, PDGFR- $\beta$, p-PLC $\gamma 1$, PLC $\gamma 1$, p-AKT, AKT, p-extracellular-regulated kinase, extracellular-regulated kinase (ERK), cyclin-dependent kinase (CDK)2, CDK4, cyclin $\mathrm{D} 1$, cyclin $\mathrm{E}$ and $\beta$-actin at dilutions of 1:1000 overnight at $4^{\circ} \mathrm{C}$. The bands were detected using a chemiluminescence kit (Pierce). Densitometry analysis was performed with Lab Image software (Scion Corporation).

\section{Angioplasty balloon surgery}

Balloon injury in rats was performed as described previously $^{(32)}$. All surgical procedures were performed according to the principles of the Kyungpook National University Animal Care and the Guild for the Care and Use of Laboratory Animals. The animals were divided into four groups: negative control (vehicle alone, $n 3$ ); balloon injured only ( $n$ 3); balloon injured plus DGC ( $0.5 \mathrm{mg}, n 3)$; balloon injured plus DGC (1 mg, $n 3$ ); balloon injured plus DGC (2 mg, $n 3$ ). Male Sprague-Dawley rats, 8 weeks old (Daehan Biolink), were anaesthetised using an intraperitoneal injection of Zoletil ( $1 \mathrm{ml} / \mathrm{kg}$ body weight) and Rompun $(0.25 \mathrm{ml} / \mathrm{kg}$ body weight). The right carotid artery was surgically exposed and injured using a balloon catheter (Edwards Lifescience). After balloon injury, $100 \mu \mathrm{l}$ of Pluronic gel with or without DGC were applied to the adventitial surface of the injured carotid rat artery.

\section{Tissue preparation and morphological analysis}

Carotid arteries were dissected, rinsed with physiological saline and weighed. The tissues were fixed in $10 \%$ buffered

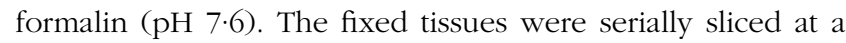
thickness of $5.0 \mu \mathrm{m}$ using a microtome (Model RM 2125RT; Leica Microsystems). The sections were stained with Harry's haematoxylin-eosin, and the luminal, neointimal and medial areas of the different sections were quantified with light microscopy and an image analysis program (NIS-Elements F3.00; Nikon Corporation).

\section{Statistical analysis}

Data were tested by ANOVA, followed by Duncan's multiple range test, using SPSS software (SPSS, Inc.). The level of significance was set at $P<0 \cdot 05$.

\section{Results}

Effects of dehydroglyasperin C on human aortic smooth muscle cell proliferation and platelet-derived growth factor-stimulated cycle progression

When HASMC were stimulated by PDGF-BB $(20 \mathrm{ng} / \mathrm{ml})$, the number of cells was increased by about $35 \%$ compared with the control group. Treatment of PDGF-stimulated HASMC with DGC $(0 \cdot 1-1 \mu \mathrm{M})$ resulted in a significant decrease in cell number, which was not a result of cell death. The ratio of inhibition was $17 \cdot 3$ (SD 3.0), $15 \cdot 7$ (SD 7.8) and 31.0 (SD 6.7) \% at 0.1, 0.5 and $1 \mu \mathrm{M}$, respectively (Fig. 2(A)). There was no significant change in cell morphology in the cultures treated with PDGF plus DGC (data not shown).

To confirm the effect of DGC on VSMCC proliferation, we performed DNA synthesis analysis. The effect of DGC on DNA synthesis was assayed by $\left[{ }^{3} \mathrm{H}\right]$ thymidine incorporation. 
(A)

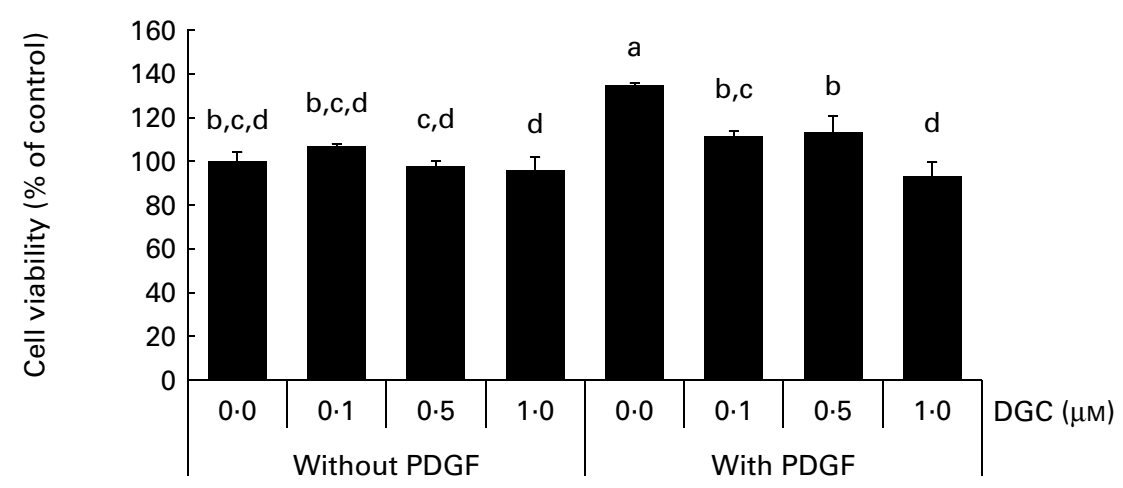

(B)

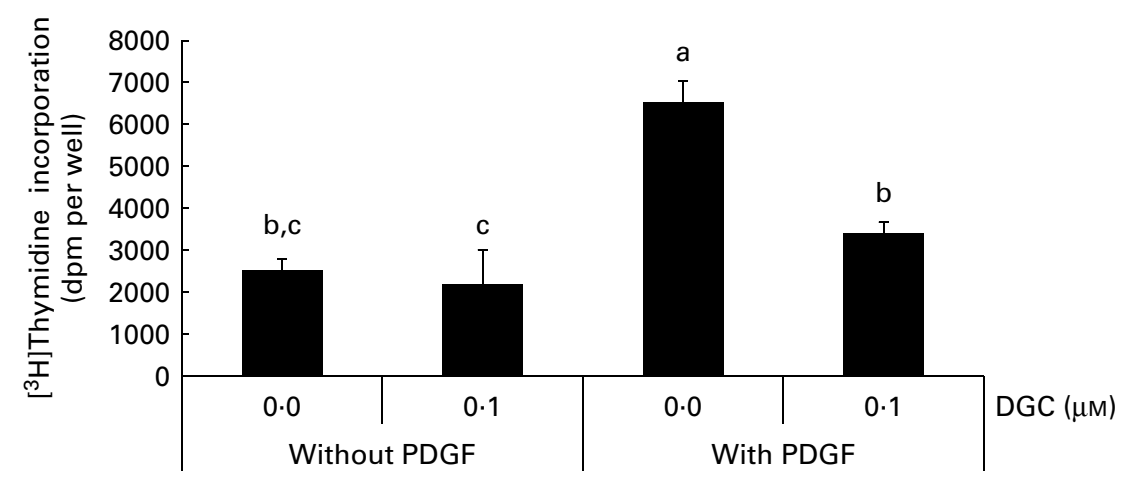

Fig. 2. Effects of dehydroglyasperin $C$ (DGC) on platelet-derived growth factor (PDGF)-induced proliferation of human aortic smooth muscle cells (HASMC). HASMC were treated with or without $1 \mu \mathrm{M}-\mathrm{DGC}$ in the presence or absence of $20 \mathrm{ng} / \mathrm{ml}$ PDGF after pre-incubation with or without DGC for $24 \mathrm{~h}$. After incubation for $20-24 \mathrm{~h}$, the cells were processed for the 3-(4,5-dimethyl-thiazol-2-yl)-2,5-diphenyltetrazolium bromide assay (A) or $\left[{ }^{3} \mathrm{H}\right]$ thymidine incorporation (B) as described in the Experimental methods section. Values are means of three separate independent experiments, with standard deviations represented by vertical bars. ${ }^{a, b, c, d}$ Mean values with unlike letters were significantly different $(P<0.05)$.

As shown in Fig. 2(B), incubation of the cells with $20 \mathrm{ng} / \mathrm{ml}$ of PDGF led to a significant increase in $\left[{ }^{3} \mathrm{H}\right]$ thymidine incorporation, which corresponded to approximately a $2 \cdot 6$-fold increase in vehicle-stimulated cells. DGC effectively inhibited the PDGF-induced $\left[{ }^{3} \mathrm{H}\right]$ thymidine incorporation into DNA. The inhibition percentage of DGC was about 47.9 (SD $4 \cdot 1$ ) \% at $1 \mu \mathrm{M}$. These data demonstrate that DGC blocks DNA synthesis in VSMC, resulting in the attenuation of proliferation.

The DNA content was also analysed by propidium iodide staining to investigate the effect of DGC on cell cycle progression in HASMC. PDGF-BB induced an increase in the $\mathrm{S}$ phase from 3.4 to $30.5 \%$ compared with the non-stimulated cells. DGC decreased the accumulation at the $\mathrm{S}$ phase to $4.6 \%$ with $0.1 \mu \mathrm{m}, 5.9 \%$ with $0.5 \mu \mathrm{m}$ and $5.7 \%$ with $1 \mu \mathrm{m}$ in PDGF-treated cells. These results indicate that DGC was effective in arresting PDGF-stimulated cell cycle progression in HASMC (Fig. 3(A) and (B)).

\section{Effects of dehydroglyasperin C on the expression of cell cycle-related proteins}

Growth factors increase the expression of cyclin D1 in the $G_{1}$ phase of the cell cycle to allow entry of the cells into the $\mathrm{S}$ phase. Cell cycle progression is tightly regulated through a complex network of positive and negative cell-cycle regulatory molecules such as $\mathrm{CDK}$ and cyclins. Along with CDK4, the expression of cyclin E-dependent kinase CDK2 is also essential for the progression of the cells from the $G_{1}$ to the $S$ phase ${ }^{(33)}$. To investigate whether the inhibition of proliferation by DGC is involved in the regulation of cell cyclerelated proteins, we assessed the expression of $\mathrm{G}_{1}$-checkpoint proteins in DGC-treated cycle-arrested cells. As shown in Fig. 3(C), we observed slightly decreased levels of CDK4, cyclin D1, CDK2 and cyclin E in cells incubated with DGC $(1 \mu \mathrm{M})$. Therefore, these findings suggest that DGC affects the transition of HASMC from the $G_{1}$ to the $S$ phase, together with its inhibitory effects on HASMC proliferation.

\section{Effects of dehydroglyasperin $C$ on the platelet-derived growth factor-induced signalling pathway}

Several phospho-specific antibodies were used to quantify the PDGF-regulated downstream molecules. PDGF-induced activated proteins such as PDGFR- $\beta$, PLC $\gamma 1$ and AKT were detected to determine the inhibitory mechanism of DGC on the signal transduction pathway of PDGF for HASMC proliferation and migration. HASMC were stimulated with PDGF-BB $(20 \mathrm{ng} / \mathrm{ml})$ for $15 \mathrm{~min}$, which caused the obvious phosphorylation of PDGFR- $\beta$, PLC $\gamma 1$ and AKT, and the increased phosphorylation 


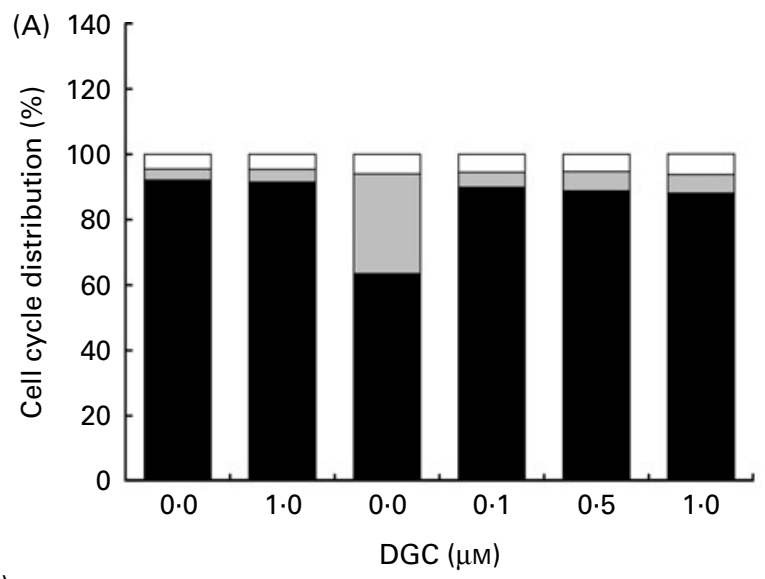

(B)
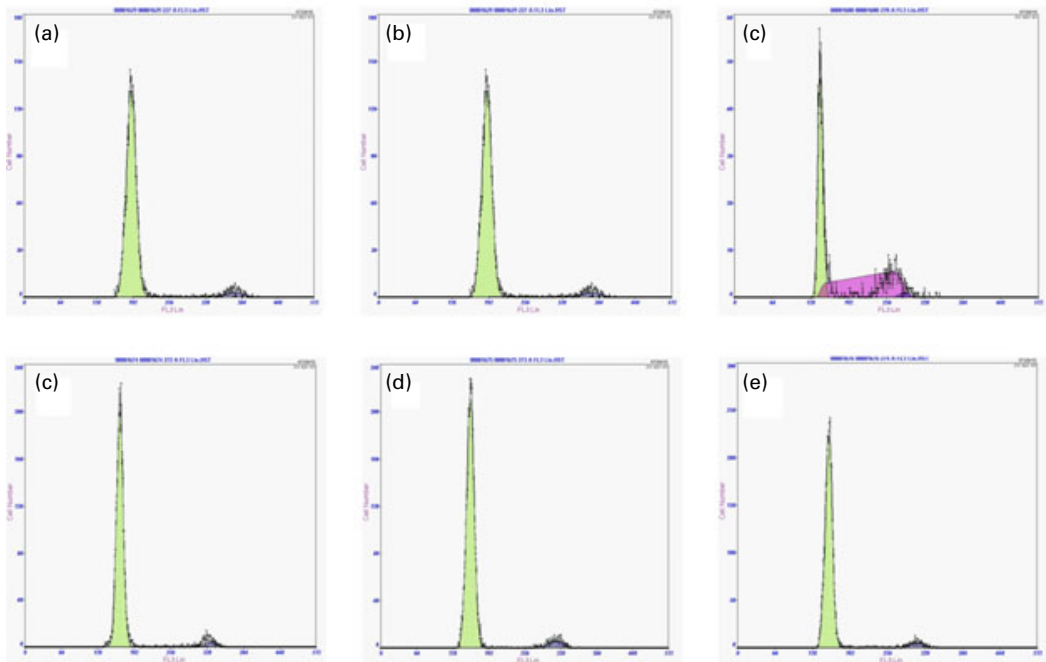

(C)

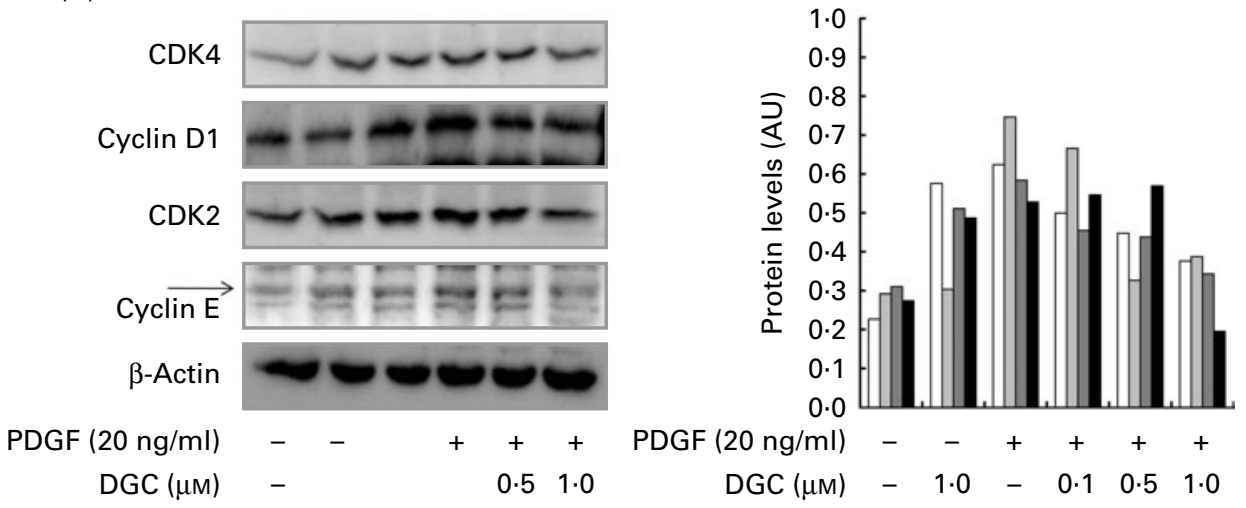

Fig. 3. Effects of dehydroglyasperin C (DGC) on cell cycle progression in human aortic smooth muscle cells (HASMC) stimulated by platelet-derived growth factor (PDGF). HASMC were treated as described in Fig. 2. (A) Representative DNA histograms of propidium iodide fluorescence in cells assessed by flow cytometry are shown. $\square, G_{2} / M ; \square, S ; n, G_{0} / G_{1}$. (B) For evaluation of the expression of proteins related to cell cycle progression, whole-cell extracts $(20 \mu \mathrm{g})$ were subjected

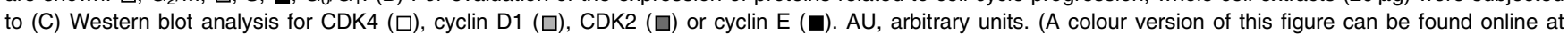
http://www.journals.cambridge.org/bjn).

was suppressed with various concentrations of DGC $(0 \cdot 1,0 \cdot 5$ and $1 \mu \mathrm{M})$, suggesting that the anti-proliferative effect of DGC was implicated in the early signal transduction by PDGF (Fig. 4(A)-(C)). Since PDGF is capable of inducing the activation of mitogen-activated protein kinases for VSMC proliferation $^{(9)}$, we investigated the effects of DGC on the PDGF signalling pathway by measuring the phosphorylation levels of ERK1/2 with Western blotting (Fig. 4(D)) in HASMC. The results showed that PDGF substantially increased ERK1/2 phosphorylation, whereas cells incubated with DGC at various concentrations $(0 \cdot 1,0.5$ and $1 \mu \mathrm{M})$ diminished ERK1/2 phosphorylation in a dose-dependent manner. 
(A)
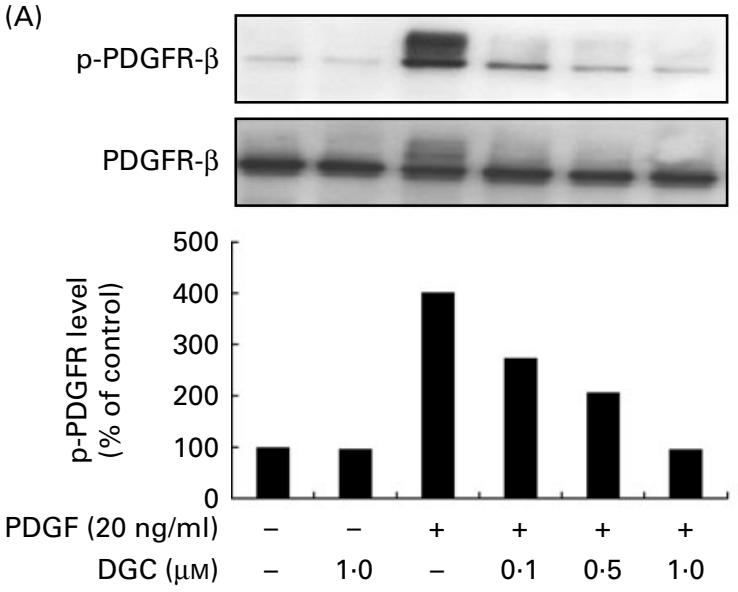

(C)

Effects of dehydroglyasperin C on platelet-derived growth factor-stimulated migration of human aortic smooth muscle cells

VSMC migration is affected by the stimulation of PDGFR- $\beta$ by $\mathrm{PDGF}^{(32)}$. In order to investigate the effects of DGC on HASMC migration, the cells were treated for $24 \mathrm{~h}$ with different concentrations of DGC in the presence or absence of PDGF in a Boyden chamber. The cells migrated to the lower chamber were stained with calcein acetoxymethyl ester, and were photographed with a fluorescence microscope. As shown in Fig. 5, treatment with DGC alone had no significant effect on HASMC migration compared with the vehicle-treated cells. However, PDGF significantly increased the migration up to about 304.4 (SD 29.1)\%, while DGC effectively inhibited the PDGF-stimulated cell migration at $1 \mu \mathrm{m}$.

\section{Effects of dehydroglyasperin $C$ on the rearrangement of} actin filaments induced by platelet-derived growth factor

Regardless of the cell type, since effective reorganisation of the actin cytoskeleton is absolutely important for migration ${ }^{(34)}$, we attempted to determine the effects of DGC on the PDGF-induced rearrangement of actin filaments (Fig. 6).
(B)
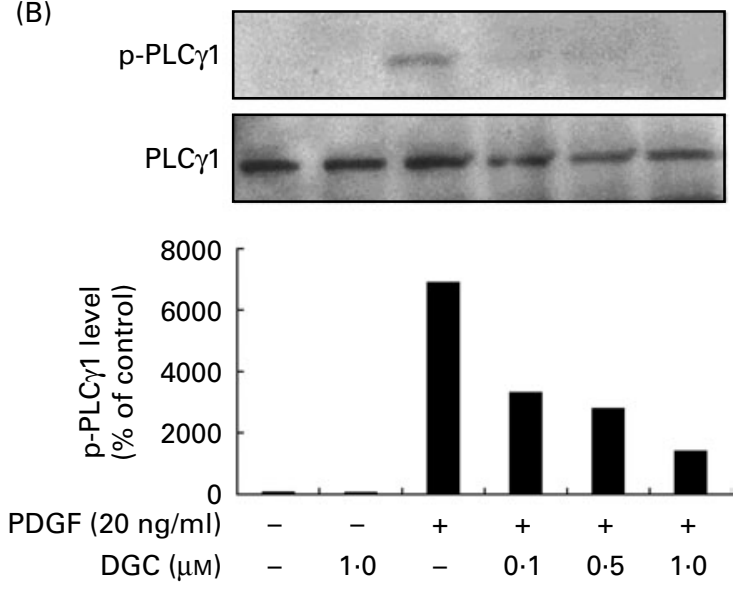

(D)
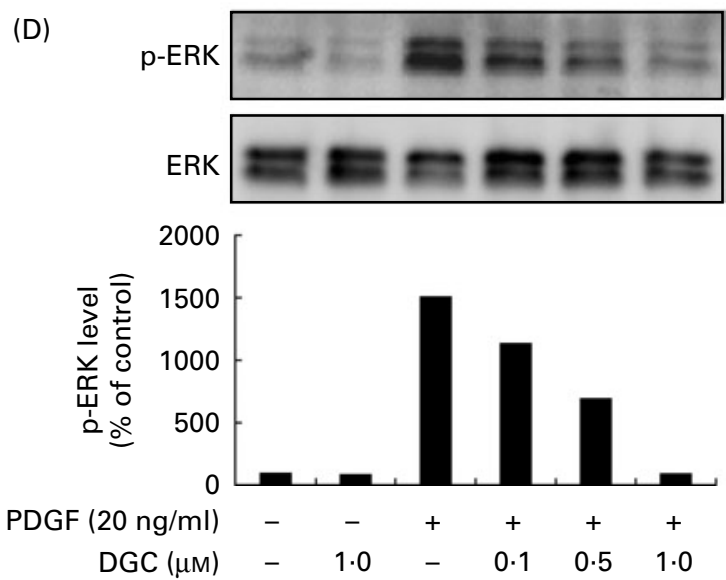

Fig. 4. Effects of dehydroglyasperin $C$ (DGC) on the platelet-derived growth factor (PDGF) signalling pathway. Western blot of the phosphorylation of (A) PDGF receptor- $\beta$ (PDGFR- $\beta$ ), (B) phospholipase C- $\gamma 1$ (PLC $\gamma 1$ ) and (C) AKT, and (D) the activation of mitogen-activated protein kinases was performed for human aortic receptor- $\beta$ (PDGFR- $\beta$ ), (B) phospholipase C- $\gamma 1$ (PLC $\gamma 1$ ) and (C) AKT, and (D) the activation of mitogen-activated prot
smooth muscle cells treated with or without $20 \mathrm{ng} / \mathrm{ml}$ of PDGF-BB for $15 \mathrm{~min}$ after pre-incubation with DGC for $24 \mathrm{~h}$. 

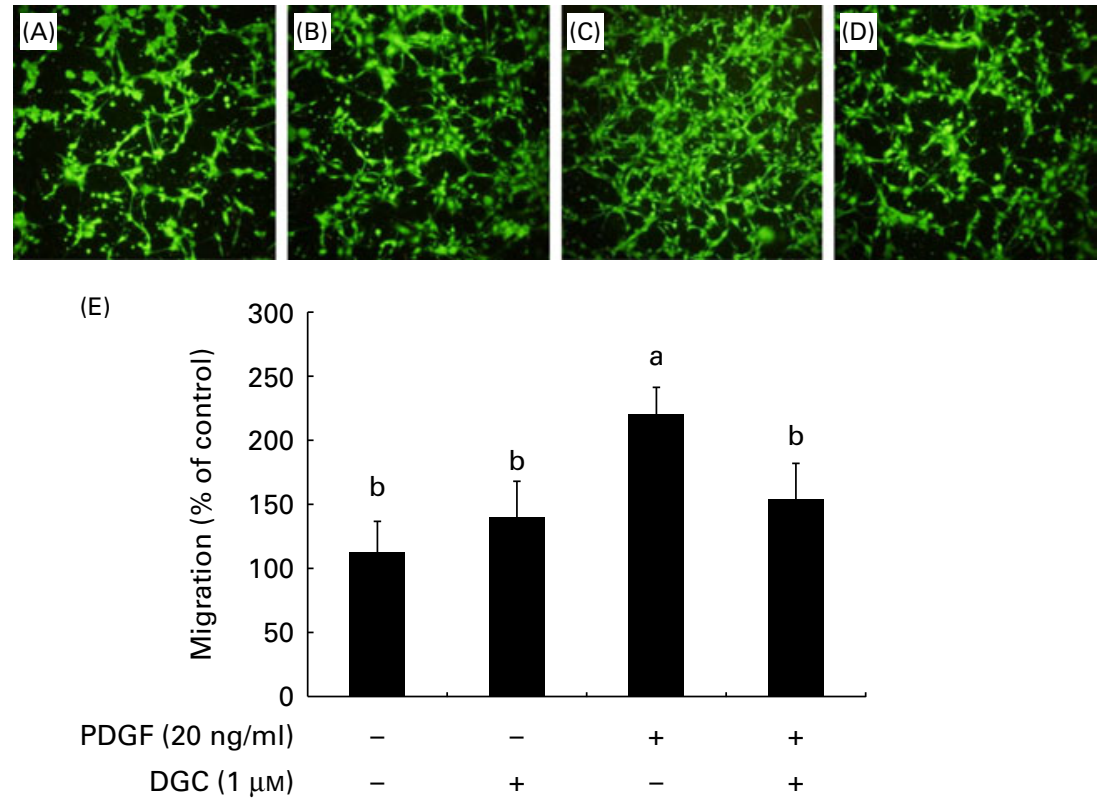

Fig. 5. Effects of dehydroglyasperin C (DGC) on platelet-derived growth factor (PDGF)-induced migration of human aortic smooth muscle cells (HASMC). HASMC were seeded onto the transwell plate with or without $1 \mu \mathrm{M}$-DGC in the presence or absence of $20 \mathrm{ng} / \mathrm{ml}$ of PDGF-BB for $24 \mathrm{~h}$. The migrated HASMC were analysed with fluorescence calcein acetoxymethyl ester staining. The representative photomicrographs of the migrated cells to the lower chambers after calcein acetoxymethyl ester staining are shown as follows: (A) control; (B) DGC $(1 \mu \mathrm{M})$; (C) PDGF; (D) PDGF + DGC $(1 \mu \mathrm{M})$. The percentage of migrated cells relative to the control is shown in the bar graph $(E)$. Values are means of three separate independent experiments, with standard deviations represented by vertical bars. ${ }^{a, b}$ Mean values with unlike letters were significantly different $(P<0.05)$. (A colour version of this figure can be found online at http://www.journals.cambridge.org/bjn).

gel group in a dose-dependent manner (balloon injured plus DGC (0.5 mg), approximately $38 \%$; balloon injured plus DGC (1 mg), approximately 68\%; balloon injured plus DGC (2 mg), approximately $84 \%$ ).
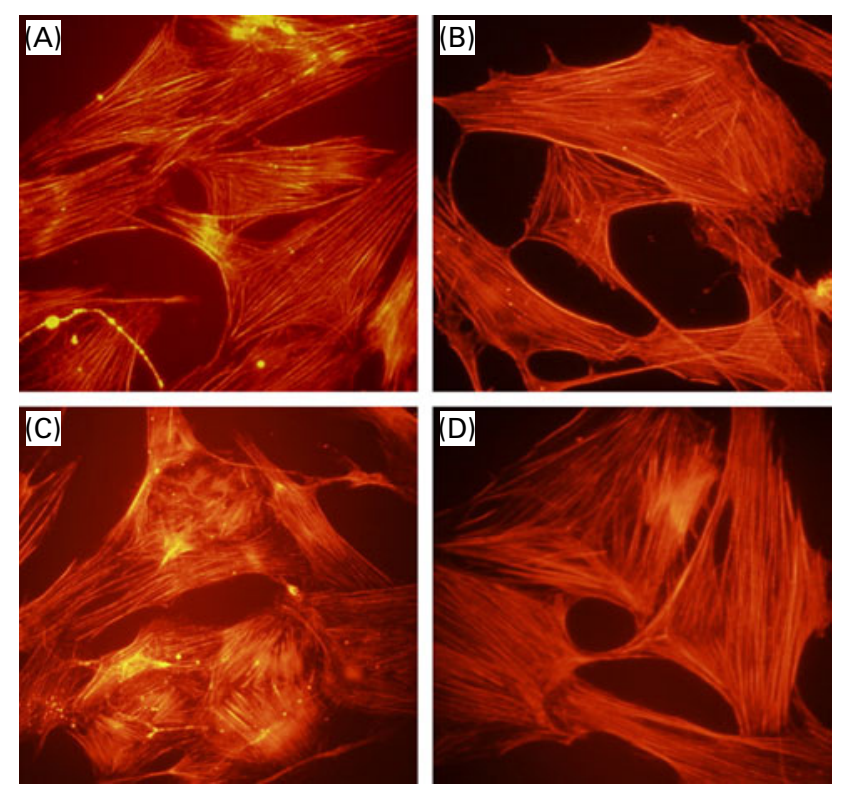

Fig. 6. Effects of dehydroglyasperin $C$ (DGC) on platelet-derived growth factor (PDGF)-stimulated cytoskeletal reorganisation. The cells grown on a coverslip were treated with or without $1 \mu \mathrm{M}$-DGC in the presence or absence of $20 \mathrm{ng} / \mathrm{ml}$ of PDGF-BB for $24 \mathrm{~h}$. The cells were fixed, and the actin filaments were stained with rhodamine phalloidine and photographed using a fluorescent microscope. (A) Control; (B) DGC (1 $\mu \mathrm{M})$; (C) PDGF; (D) PDGF + DGC $(1 \mu \mathrm{M})$. Magnification $200 \times$. (A colour version of this figure can be found online at http://www.journals.cambridge.org/bjn).

\section{Discussion}

VSMC are major cells present in arterial structures, and play a very important role in the maintenance of normal vascular structures and functions. VSMC are normally quiescent, at low proliferative indices, and remain in the $G_{0} / G_{1}$ phase of the cell cycle ${ }^{(35)}$. The growth of VSMC is an indicator for the formation and development of atherosclerosis through proliferative responses and promoting the expression of other growth factors in $\operatorname{VSMC}^{(36,37)}$.

Several studies have shown that liquorice-derived compounds have beneficial effects on atherosclerotic processes including the adhesion and migration of leucocytes ${ }^{(19)}$, development of visceral obesity, regulation of HDL levels ${ }^{(18)}$ and lipidaemia ${ }^{(20)}$, and vascular growth factor-induced proliferation of $\mathrm{VSMC}^{(38)}$. In addition to vascular protective effects, liquorice is also known to possess antioxidant activity ${ }^{(16)}$.

Although the constituents of liquorice are desirable candidates acting as anti-atherosclerotic agents, little is known regarding their effects on PDGF-induced proliferation and migration of VSMC. In the present study, we tested the inhibitory effects of DGC on PDGF-induced proliferation and migration of HASMC, and attempted to explain its associated mechanisms. PDGF was used as a positive control to evaluate the effect of DGC on the proliferation of VSMC. We provide the first evidence that DGC inhibits PDGF-stimulated proliferation and DNA synthesis without induced apoptosis.

$\mathrm{pRb}, \mathrm{CDK}$, cyclins, CDK inhibitor proteins, $\mathrm{p} 21^{\text {cip1 }}$ and $\mathrm{p} 27^{\mathrm{kip} 1}$, and tumour-suppressor proteins including $\mathrm{p} 53^{(33,39,40)}$ are implicated in controlling the cell cycle for the $G_{1}, S, G_{2}$ and $M$ phases. While normal VSMC maintain the $G_{0}$ phase for a quiescent state, an increase in the accumulation of VSMC in the intima and media 
(A)
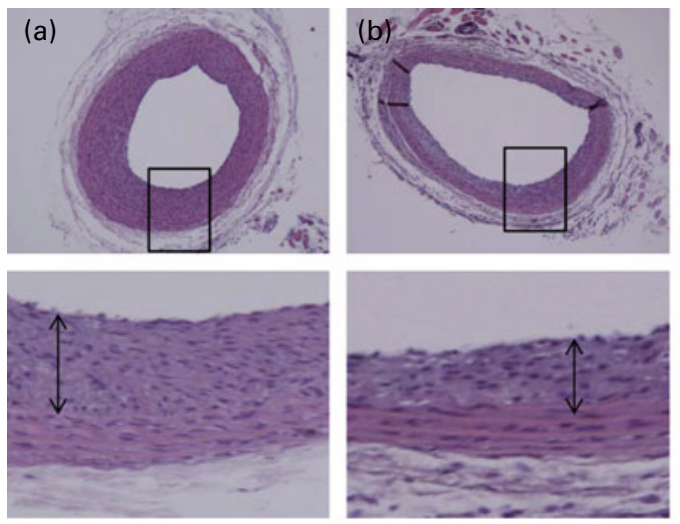
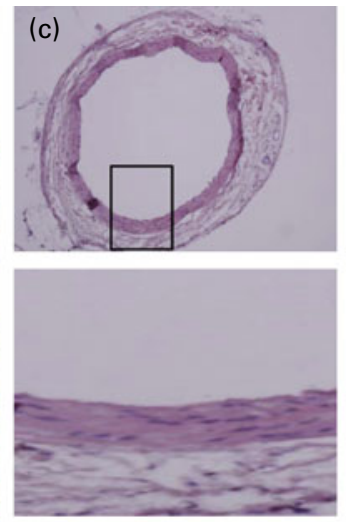
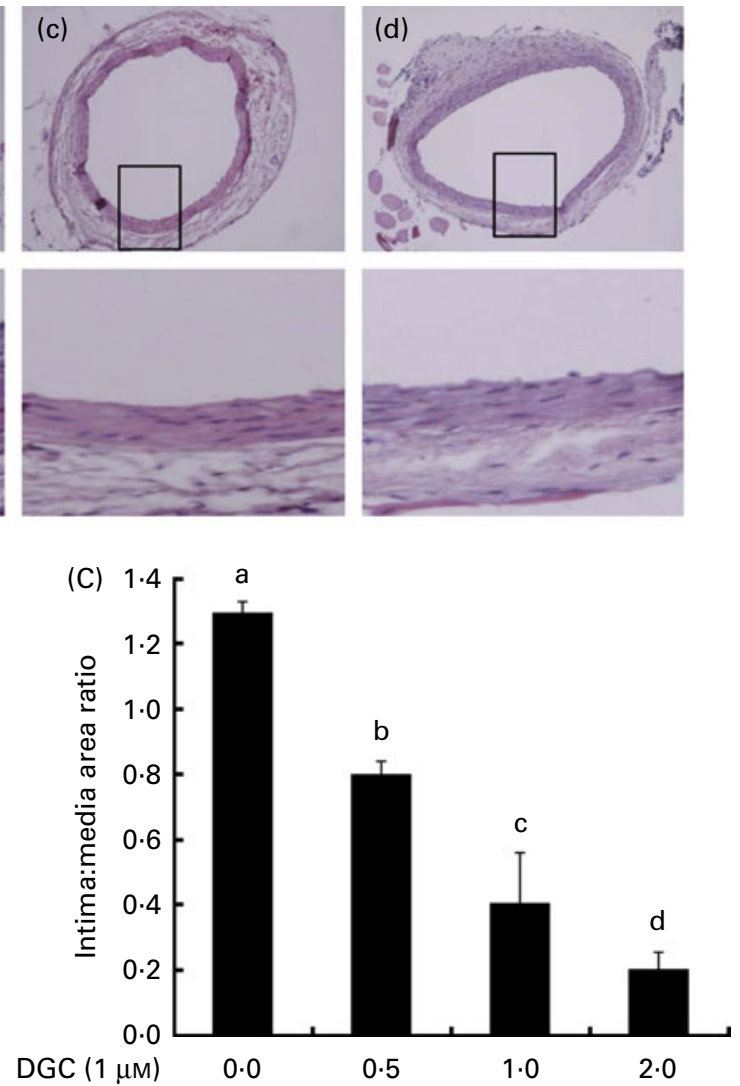

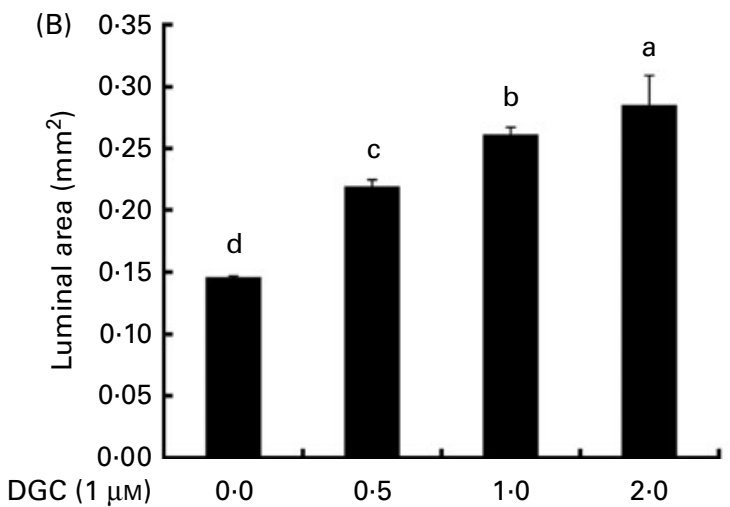

Fig. 7. Effects of dehydroglyasperin $C(D G C)$ on rat carotid artery morphology after balloon injury. DGC $(0.5$ and $1 \mathrm{mg})$ diminished the formation of intimal smooth muscle cells on the 16th day after balloon catheter injury. (A) Control (a), $0.5 \mathrm{mg} \mathrm{DGC} \mathrm{(b),} 1 \mathrm{mg}$ DGC (c) and $2 \mathrm{mg}$ DGC (d). Magnification $100 \times$ and $400 \times$. (B) Luminal area and (C) intima:media area ratios of the four groups ( $n 4$ per group). ${ }^{\mathrm{a}, \mathrm{b}, \mathrm{c}, \mathrm{d}}$ Mean values with unlike letters were significantly different $(P<0.05)$. (A colour version of this figure can be found online at http://www.journals.cambridge.org/bjn).

is related to excessive proliferation and diminished VSMC death. CDK2 and CDK4, important mediators in modulating the $\mathrm{G}_{0} / \mathrm{G}_{1^{-}}$ to S-phase progression of the cell cycle and function by building complexes with cyclin E and cyclin D1, respectively, increase the activation of $\mathrm{pRb}$ and release transcription factors, resulting in the promotion of DNA synthesis ${ }^{(33,40-42)}$. On that account, the methods controlling proliferation and reducing apoptosis in abnormal VSMC have been developed as a new therapy ${ }^{(43)}$. In the present study, DGC restrained the PDGF-induced proliferation at a concentration of $1 \mu \mathrm{m}$, which may be attributable to the arrest of the $G_{0} / G_{1}-S$ phase by reducing the expression of cyclin E/CDK2 and cyclin D1/CDK4. This reduced expression suggests that PDGF-stimulated expression of cell-cycle regulatory proteins is necessary for this inhibitory activity of DGC to alleviate the abnormal proliferation of VSMC.

PDGFR- $\beta$ was expressed in the VSMC of atherosclerotic lesions ${ }^{(44)}$. It has been reported that the activated PDGFR in PDGF-BB-stimulated VSMC produces $\mathrm{H}_{2} \mathrm{O}_{2}$, resulting in the phosphorylation of the mitogen-activated protein kinases ERK1 $12^{(45)}$ and PLC $\gamma 1^{(45-47)}$. In addition to reactive oxygen species, PDGFR- $\beta$ phosphorylated by PDGF interacts with PLC $\gamma$, Ras guanine 5 -triphosphatase-activating protein, phosphatidylinositol-3 kinase, tyrosine phosphatase $\mathrm{SH} 2$ domain-containing tyrosine phosphatase 2 (SHP-2) and members of the signal transducers and activators of the transcription family that are present in the cytoplasm ${ }^{(48)}$.
Recently, DGC among the bioactive compounds from liquorice root has been shown to induce the expression of detoxifying enzymes through the transcription factor Nrf2 in hepatoma cells ${ }^{(29)}$, and exhibited antioxidant activity against 2,2'-azino-bis(3-ethylbenzothiazoline-6-sulfonic acid) $\left(\mathrm{ABTS}^{+}\right.$) radicals ${ }^{(49)}$. In our preliminary study, DGC showed an antioxidant property in rat tissues (data not shown), which has been proved by a significant inhibition of lipid peroxidation, increased proliferation of oestrogen receptor (ER)-positive MCF-7 cells, elevated oestrogenic activity on yeast-based ER activity and higher affinity to ER- $\beta$ than to ER- $\alpha$. The animal study performed by Hsieh et al. ${ }^{(50)}$ also demonstrated that an $\alpha$-tocopherol derivative inhibited PDGF-stimulated neointimal formation after angioplasty through the inhibition of reactive oxygen species-mediated PLC $\gamma 1-$ PKC $\delta$ and Janus kinase 2 (JAK2)-signal transducers and activators of transcription 3 activation, which cause the cell cycle arrest of the $\mathrm{G}_{2} / \mathrm{M}$ phase. Furthermore, the constituents derived from the plant containing antioxidant activities were elucidated to have anti-proliferative properties in vascular cells induced by PDGF ${ }^{(11)}$. Considering the correlation among atherosclerosis, the oxidation process and the influence of natural oestrogen derived from plants ${ }^{(51-53)}$, there is a possibility that DGC may control vascular growth factormediated morphological changes in the blood vessels. As expected, the present results showed that DGC regulated the 
proliferation of vascular cells by reducing Akt and PLC $\gamma 1$ in PDGF-treated HASMC.

ERK1/2 controls the PDGF-induced proliferation of VSMC through the regulation of the cell cycle modulators cyclin D1 and $\mathrm{p} 27 \mathrm{kip} 1^{(42,54-56)}$. Mitogenic stimulation activates the kinase MEK1/2 and induces the subsequent phosphorylation of ERK1/2 that activates downstream transcription factors such as Elk-1 ${ }^{(57)}$, which is involved in DNA synthesis in $\mathrm{VSMC}^{(58)}$. Consistent with previous studies, the present data showed that DGC significantly decreased the PDGF-induced phosphorylation of ERK1/2.

VSMC migration from the media to the intima in the blood vessels leads to intimal thickening. In this process, PDGF is an important migratory factor for VSMC during neointimal formation ${ }^{(59)}$. Although the mechanisms of PDGF-stimulated migration have not been fully understood so far, there are several interesting studies. For instance, PDGF-BB facilitated intimal hyperplasia through the media-to-intima migration of VSMC in an animal model ${ }^{(6)}$, and the blocking of PDGF receptor signalling markedly retarded VSMC growth and neointimal formation by injury ${ }^{(7)}$. In addition, it is known that PDGF disturbs actin filament assembly and gives rise to an excessive increase in PDGFR expression after angioplasty ${ }^{(5)}$.

Taken together, the present study demonstrates that DGC has the ability to inhibit not only PDGF-stimulated proliferation of VSMC, which is attributable to interference with the cell cycle, but also VSMC migration. The possible mechanisms of DGC responsible for inhibiting the proliferation of VSMC are related to the inactivation of PDGFR- $\beta$, PLC $\gamma 1$, AKT and ERK. The results of the present study will be helpful in better understanding the mechanism of the pharmacological activity of DGC in the treatment of atherosclerosis.

\section{Acknowledgements}

This study was supported by the Basic Science Research Program through the National Research Foundation of Korea (NRF) funded by the Ministry of Education, Science and Technology (2010-0027204). J.-S. K. and J.-T. W. planned the study. H. J. K. and B.-Y. C. performed the proliferation, Western blotting, migration and cytoskeletal reorganisation assay. H. J. K., I. S. P. and J. S. L. carried out the angioplasty balloon surgery. H. J. K., B.-Y. C. and J.-S. K. wrote the paper. The authors declared no conflict of interest.

\section{References}

1. Ross R (1993) The pathogenesis of atherosclerosis: a perspective for the 1990s. Nature 362, 801-809.

2. Raines EW (2004) PDGF and cardiovascular disease. Cytokine Growth Factor Rev 15, 237-254.

3. Jiang B, Yamamura S, Nelson PR, et al. (1996) Differential effects of platelet-derived growth factor isotypes on human smooth muscle cell proliferation and migration are mediated by distinct signaling pathways. Surgery 120, 427-431.

4. Koyama N, Hart CE \& Clowes AW (1994) Different functions of the platelet-derived growth factor-alpha and -beta receptors for the migration and proliferation of cultured baboon smooth muscle cells. Circ Res 75, 682-691.
5. Sirois MG, Simons M \& Edelman ER (1997) Antisense oligonucleotide inhibition of PDGFR-beta receptor subunit expression directs suppression of intimal thickening. Circulation 95, 669-676.

6. Jawien A, Bowen-Pope DF, Lindner V, et al. (1992) Plateletderived growth factor promotes smooth muscle migration and intimal thickening in a rat model of balloon angioplasty. J Clin Invest 89, 507-511.

7. Banai S, Wolf Y, Golomb G, et al. (1998) PDGF-receptor tyrosine kinase blocker AG1295 selectively attenuates smooth muscle cell growth in vitro and reduces neointimal formation after balloon angioplasty in swine. Circulation 97, 1960-1969.

8. Bornfeldt KE, Raines EW, Nakano T, et al. (1994) Insulin-like growth factor-I and platelet-derived growth factor-BB induce directed migration of human arterial smooth muscle cells via signaling pathways that are distinct from those of proliferation. J Clin Invest 93, 1266-1274.

9. Bornfeldt KE, Raines EW, Graves LM, et al. (1995) Plateletderived growth factor. Distinct signal transduction pathways associated with migration versus proliferation. Ann $N$ Y Acad Sci 766, 416-430.

10. Venkatesan B, Ghosh-Choudhury N, Das F, et al. (2008) Resveratrol inhibits PDGF receptor mitogenic signaling in mesangial cells: role of PTP1B. FASEB J 22, 3469-3482.

11. Kim HJ, Cha BY, Choi B, et al. (2012) Glyceollins inhibit platelet-derived growth factor-mediated human arterial smooth muscle cell proliferation and migration. BrJ Nutr 107, 24-35.

12. Mae T, Kishida H, Nishiyama T, et al. (2003) A licorice ethanolic extract with peroxisome proliferator-activated receptor-gamma ligand-binding activity affects diabetes in KK-Ay mice, abdominal obesity in diet-induced obese C57BL mice and hypertension in spontaneously hypertensive rats. $J$ Nutr 133, 3369-3677.

13. Fukai T, Marumo A, Kaitou K, et al. (2002) Anti-Helicobacter pylori flavonoids from licorice extract. Life Sci 71, 1449-1463.

14. Shin YW, Bae EA, Lee B, et al. (2007) In vitro and in vivo antiallergic effects of Glycyrrbiza glabra and its components. Planta Med 73, 257-261.

15. Gupta VK, Fatima A, Faridi U, et al. (2008) Antimicrobial potential of Glycyrrbiza glabra roots. J Ethnopharmacol 116, 377-380.

16. Chin YW, Jung HA, Liu Y, et al. (2007) Anti-oxidant constituents of the roots and stolons of licorice (Glycyrrbiza glabra). J Agric Food Chem 55, 4691-4697.

17. Zhang L, Yang Y, Yu L, et al. (2011) Cardioprotective effects of Glycyrrhiza uralensis extract against doxorubicin-induced toxicity. Int J Toxicol 30, 181-189.

18. Eu CH, Lim WY, Ton SH, et al. (2010) Glycyrrhizic acid improved lipoprotein lipase expression, insulin sensitivity, serum lipid and lipid deposition in high-fat diet-induced obese rats. Lipids Health Dis 9, 81.

19. Chang YL, Chen CL, Kuo CL, et al. (2010) Glycyrrhetinic acid inhibits ICAM-1 expression via blocking JNK and NF-kappaB pathways in TNF-alpha-activated endothelial cells. Acta Pharmacol Sin 31, 546-553.

20. Lim WY, Chia YY, Liong SY, et al. (2009) Lipoprotein lipase expression, serum lipid and tissue lipid deposition in orally-administered glycyrrhizic acid-treated rats. Lipids Health Dis 8, 31.

21. Haraguchi H, Ishikawa H, Mizutani K, et al. (1998) Antioxidative and superoxide scavenging activities of retrochalcones in Glycyrrbiza inflata. Bioorg Med Chem 6, 339-347.

22. Shibata S (2000) A drug over the millennia: pharmacognosy, chemistry, and pharmacology of licorice. Yakugaku Zasshi 120, 849-862. 
23. Kondo K, Shiba M, Yamaji H, et al. (2007) Species identification of licorice using nrDNA and cpDNA genetic markers. Biol Pharm Bull 30, 1497-1502.

24. Kuroda M, Mimaki Y, Sashida Y, et al. (2003) Phenolics with PPAR-gamma ligand-binding activity obtained from licorice (Glycyrrbiza uralensis roots) and ameliorative effects of glycyrin on genetically diabetic KK-A(y) mice. Bioorg Med Chem Lett 13, 4267-4272.

25. Hatano T, Shintani Y, Aga Y, et al. (2000) Phenolic constituents of licorice. VIII. Structures of glicophenone and glicoisoflavanone, and effects of licorice phenolics on methicillin-resistant Staphylococcus aureus. Chem Pharm Bull (Tokyo) 48, 1286-1292.

26. Li J, Lim SS, Lee ES, et al. (2011) Isoangustone A suppresses mesangial fibrosis and inflammation in human renal mesangial cells. Exp Biol Med (Maywood) 236, 435-444.

27. Seon MR, Park SY, Kwon SJ, et al. (2012) Hexane/ethanol extract of Glycyrrbiza uralensis and its active compound isoangustone A induce $G_{1}$ cycle arrest in DU145 human prostate and 4T1 murine mammary cancer cells. $J$ Nutr Biochem 23, 85-92.

28. Seon MR, Lim SS, Choi HJ, et al. (2010) Isoangustone A present in hexane/ethanol extract of Glycyrrbiza uralensis induces apoptosis in DU145 human prostate cancer cells via the activation of DR4 and intrinsic apoptosis pathway. Mol Nutr Food Res 54, 1329-1339.

29. Seo JY, Park J, Kim HJ, et al. (2009) Isoalantolactone from Inula helenium caused Nrf2-mediated induction of detoxifying enzymes. $J$ Med Food 12, 1038-1045.

30. Cha BY, Shi WL, Yonezawa T, et al. (2009) An inhibitory effect of chrysoeriol on platelet-derived growth factor (PDGF)-induced proliferation and PDGF receptor signaling in human aortic smooth muscle cells. J Pharmacol Sci 110, 105-110.

31. Erl W, Weber C \& Hansson GK (2000) Pyrrolidine dithiocarbamate-induced apoptosis depends on cell type, density, and the presence of $\mathrm{Cu}(2+)$ and $\mathrm{Zn}(2+)$. Am J Physiol Cell Physiol 278, 1116-1125.

32. Clowes AW, Reidy MA \& Clowes MM (1983) Kinetics of cellular proliferation after arterial injury. I. Smooth muscle growth in the absence of endothelium. Lab Invest 49, 327-333.

33. Sherr CJ \& Roberts JM (1999) CDK inhibitors: positive and negative regulators of $\mathrm{G}_{1}$-phase progression. Genes Dev $\mathbf{1 3}$ 1501-1512.

34. dos Remedios CG, Chhabra D, Kekic M, et al. (2003) Actin binding proteins: regulation of cytoskeletal microfilaments. Physiol Rev 83, 433-473.

35. Xiong Y, Hannon GJ, Zhang H, et al. (1993) p21 is a universal inhibitor of cyclin kinases. Nature 366, 701-704.

36. Ferns GA, Raines EW, Sprugel KH, et al. (1991) Inhibition of neointimal smooth muscle accumulation after angioplasty by an antibody to PDGF. Science 253, 1129-1132.

37. Newby AC \& Zaltsman AB (2000) Molecular mechanisms in intimal hyperplasia. J Pathol 190, 300-309.

38. Park JH, Lim HJ, Lee KS, et al. (2008) Anti-proliferative effect of licochalcone A on vascular smooth muscle cells. Biol Pharm Bull 31, 1996-2000.

39. Braun-Dullaeus RC, Mann MJ, Sedding DG, et al. (2004) Cell cycle-dependent regulation of smooth muscle cell activation. Arterioscler Thromb Vasc Biol 24, 845-850.

40. Sherr CJ (1996) Cancer cell cycles. Science 274, 1672-1677.

41. Jirawatnotai S, Aziyu A, Osmundson EC, et al. (2004) Cdk4 is indispensable for postnatal proliferation of the anterior pituitary. J Biol Chem 279, 51100-51106.
42. Martin A, Odajima J, Hunt SL, et al. (2005) Cdk2 is dispensable for cell cycle inhibition and tumor suppression mediated by p27(Kip1) and p21(Cip1). Cancer Cell 7, 591-598.

43. Guevara NV, Chen KH \& Chan L (2001) Apoptosis in atherosclerosis: pathological and pharmacological implications. Pharmacol Res 44, 59-71.

44. Wilcox JN, Smith KM, Williams LT, et al. (1998) Plateletderived growth factor mRNA detection in human atherosclerotic plaques by in situ hybridization. J Clin Invest $\mathbf{8 2}$, 1134-1143.

45. Sundaresan M, Yu ZX, Ferrans VJ, et al. (1995) Requirement for generation of $\mathrm{H}_{2} \mathrm{O}_{2}$ for platelet-derived growth factor signal transduction. Science 270, 296-299.

46. Brown DI \& Griendling KK (2009) Nox proteins in signal transduction. Free Radic Biol Med 47, 1239-1253.

47. Choi MH, Lee IK, Kim GW, et al. (2005) Regulation of PDGF signalling and vascular remodelling by peroxiredoxin II. Nature 435, 347-353.

48. Heldin CH \& Westermark B (1999) Mechanism of action and in vivo role of platelet-derived growth factor. Physiol Rev 79, 1283-1316.

49. Lee YS, Kim SH, Kim JK, et al. (2010) Rapid identification and preparative isolation of antioxidant components in licorice. J Sep Sci 33, 664-671.

50. Hsieh CY, Liu CL, Hsu MJ, et al. (2010) Inhibition of vascular smooth muscle cell proliferation by the vitamin E derivative pentamethylhydroxychromane in an in vitro and in vivo study: pivotal role of hydroxyl radical-mediated PLCgamma1 and JAK2 phosphorylation. Free Radic Biol Med 49, 881-893.

51. Sosroseno W, Bird PS \& Seymour GJ (2003) Intracellular proteins involved in Porphyromonas gingivalis-induced opsonophagocytic activities of a murine macrophage cell line (RAW 264.7 cells). J Microbiol Immunol Infect 36, 229-235.

52. Pan W, Ikeda K, Takebe M, et al. (2001) Genistein, daidzein and glycitein inhibit growth and DNA synthesis of aortic smooth muscle cells from stroke-prone spontaneously hypertensive rats. J Nutr 131, 1154-1158.

53. Kim HJ, Suh HJ, Kim JH, et al. (2010) Estrogenic activity of glyceollins isolated from soybean elicited with Aspergillus sojae. J Med Food 13, 382-390.

54. Wei GL, Krasinski K, Kearney M, et al. (1997) Temporally and spatially coordinated expression of cell cycle regulatory factors after angioplasty. Circ Res 80, 418-426.

55. Lavoie JN, L'Allemain G, Brunet A, et al. (1996) Cyclin D1 expression is regulated positively by the p42/p44MAPK and negatively by the p38/HOGMAPK pathway. J Biol Chem 271, 20608-20616.

56. Castro C, Diez-Juan A, Cortes MJ, et al. (2003) Distinct regulation of mitogen-activated protein kinases and p27Kip1 in smooth muscle cells from different vascular beds. A potential role in establishing regional phenotypic variance. $J$ Biol Chem 278, 4482-4490.

57. Yang Z, Madinova A, Kozai T, et al. (2002) Felodipine inhibits nuclear translocation of p42/44 mitogen-activated protein kinase and human smooth muscle cell growth. Cardiovasc Res 53, 227-231.

58. Adam RM, Borer JG, Williams J, et al. (1999) Amphiregulin is coordinately expressed with heparin-binding epidermal growth factor-like growth factor in the interstitial smooth muscle of the human prostate. Endocrinology 140, 5866-5875.

59. Jalvy S, Renault MA, Leen LL, et al. (2007) Autocrine expression of osteopontin contributes to PDGF-mediated arterial smooth muscle cell migration. Cardiovasc Res 75, 738-747. 